\title{
Trace Elements, Minerals, Retinol and $\alpha$-Tocoferol in Calves Persistently Infected with Bovine Virus Diarr- hoea Virus
}

A number of disease conditions including acute and chronic infections in man and animal can result in hypercupremia and decreased blood levels of zinc, iron (Kaneko 1989) and selenium (Srinivas et al. 1988). It has been postulated that Interleukin 1 (Il-1) released by activated phagocytes is responsible for sequestring zinc in the liver, where it is required for synthesis of protein essential for a normal host defence (Dinarello 1984). It has also been suggested that Il-1 induces a granulocyte release of lactoferrin which binds iron and induces hypoferraemia probably through increased hepatic uptake of the lactoferrin-iron complex (Goldblum et al. 1987). The hypercupremia is owing to the stimulation of ceruloplasmin synthesis and the release of ceruloplasmin from the liver ( $\mathrm{Cou}$ sins 1985). Low plasma levels of vitamins A and $E$ have been descriebed in relation to infectious diseases, e.g., mastitis (Blencha and Charley 1990). Srinivas et al. (1988) report that human patients with viral infections have hypercupremia but not significant alterations in the levels of zinc, iron and selenium in plasma. In sheep with border disease, a disease caused by a congenital infection with a pestivirus, the copper is reported to be reduced in serum, cerebral tissues and possibly in the liver but increased in the spinal cord (Patterson et al. 1974). An 18month old bull with mucosal disease, which was hospitalized and later euthanized at the clinic, Department of Cattle and Sheep Diseases, Uppsala, had low levels of iron (12 $\mu \mathrm{mol} / \mathrm{kg})$, zinc $(8 \mu \mathrm{mol} / \mathrm{kg})$, selenium $(0.25$ $\mu \mathrm{mol} / \mathrm{kg})$, retinol $(0.43 \mu \mathrm{mol} / \mathrm{kg})$ and $\alpha$-tocoferol $(1.17 \mu \mathrm{mol} / \mathrm{kg})$ in serum. The copper concentration was normal in serum (13 $\mu \mathrm{mol} / \mathrm{kg})$ but suboptimal in liver $(0.39$ $\mathrm{mmol} / \mathrm{kg}$ wet weight). Mucosal disease is a terminal stage of a persistent infection with bovine virus diarrhoea virus (BVDV), a virus which is closely related to border disease virus. The low levels of both trace elements and vitamins in the bull could be due to the persistent BVDV infection per se or the consequence of the long period of diarrhoea and inappetens the bull had before it was sampled.

To elucidate if a persistent BVDV infection influnce the levels of trace elements, minerals and vitamins, blood samples were taken from 107 to 8-month old calves of Swedish Red and White breed in a dairy herd with an ongoing BVDV infection. Five of the calves were considered to be persistently infected with BVDV since a non-cytopathic strain of the virus was isolated on 2 occasions 1 month apart and since they did not seroconvert during the same period. The 5 other calves were seropositive and served as controls. All calves were fed the same feed and were clinically healthy when sampled. However, 2 of the persistently infected calves were small in relation to their age. 


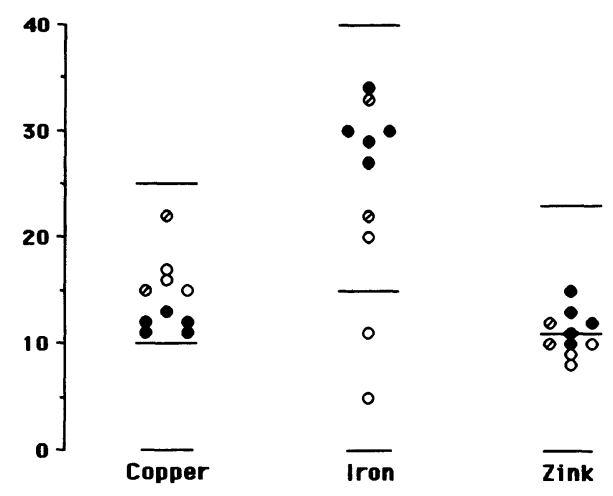

Figure 1. The levels of copper, iron and zinc in plasma from 3 normal-sized $(O)$ and 2 under-sized $(\varnothing)$ persistently BVDV-infected calves and 5 control calves ( $)$. The lines indicate the referece limits as used by the laboratory.

The chemical analyses were performed according to routine methods of the Department of Chemistry, National Veterinary Institute, Uppsala. In brief, the metal concentrations in oxidizing acid digested blood plasma were determined by simultaneous multi-element atomic-emission spectrometry. Selenium analysis was performed by continous reduction with sodium borohydride in a flow injection analysis apparatus and atomic absorption spectrometry. Retinol and $\alpha$-tocopherol were analysed with HPLC and fluorescence detection.

The concentrations of copper, iron and zinc in plasma are shown in Fig. 1. The concentration of copper in plasma was signtificantly $(\mathrm{p}<0.005)$ higher in the persistently BVDVinfected calves $(17.0 \pm 1.3 \mu \mathrm{mol} / \mathrm{kg}$, mean \pm standard deviation) than in the control group $(11.8 \pm 0.4 \mu \mathrm{mol} / \mathrm{kg})$. This result differ from the low levels of copper found in sheep with border disease (Patterson et al. 1974) but agrees with the general findings during viral infection in humans (Srinivas et al. 1988). The iron level was significantly $(\mathrm{p}<0.05)$ lower in the persistently infected calves (18.2 $\pm 4.8 \mu \mathrm{mol} / \mathrm{kg})$ than in controls $(30.1 \pm 1.1$ $\mu \mathrm{mol} / \mathrm{kg}$ ) and support previous observations (Kaneko 1989). All 10 calves had rather low levels of zinc; 4 out of 5 in the BVDV-infected group and 1 out of 5 in the control group had values below the laboratory reference limit, but there was no significant $(\mathrm{p}<0.06)$ difference between the groups. The concentrations of calcium, magnesium, phosphorus, selenium, retinol and $\alpha$-tocopherol were in the same ranges in both groups of calves. However, the concentration of phosphorus was higher in 5 calves and the concentration of $\alpha$-tocopherol was lower in 6 calves than the laboratory reference limits. The absence of significant alterations of zinc and selenium is by Srinivas et al. (1988) supposed to be representative for viral infections.

The altered plasma concentrations of copper and iron in the persistently BVDV-infected but clinically healthy calves in the present study indicate the changes to be host response to the presence of the virus.

\section{Acknowledgement}

The authors express their gratitude for financial support from the National Veterinary Institute, Uppsala.

Sten-Olof Jacobsson, Bengt Larsson and, Jan Luthman, Department of Cattle and Sheep Diseases, Swedish University of Agricultural Sciences, Uppsala, Sweden.

Adrian Frank and Stefan Alenius, Department of Chemistry and Department of Virology, National Veterinary Institute, Uppsala, Sweden.

\section{References}

Blencha F, Charley B: Immunomodulation in domestic food animals. Adv. vet. sci. compar. Med. Academic Press Inc., London. 1990, 35, 255-275.

Cousins RJ: Absorption transport and hepatic metabolism of copper and zinc: special reference to metallothionein and ceruloplasmin. Physiol. Rev. 1985, 65, 238-309. 
Dinarello CA: Interleukin-1. Rev. infect. Dis. 1984, 6, 51-75.

Goldblum SE, Cohen DA, Jay M, McClain CJ: Interleukin 1-induced depression of iron and zinc: role of granulocytes and lactoferrin. Amer. J. Physiol. 1987, 252, E27-E32.

Kaneko JJ: Clinical biochemistry of domestic animals. $4^{\text {th }}$ ed. Academic Press Inc., London. 1989, pp 932.
Patterson DSP, Brush PJ, Foulkes JA, Sweasey D: Copper metabolism and the composition of wool in border disease. Vet. Rec., 1974, 95, 214215.

Srinivas $U$, Braconier JH, Jeppsson B, Abdulla $M$, Åkesson B, Öckerman PA: Trace element alteration in infectious diseases. Scand. J. clin. Lab. Invest. 1988, 48, 495-500.

(Received February 24, 1992; Accepted March 4, 1992).

Reprints may be requested from: Sten-Olof Jacobsson, Department of Cattle and Sheep Diseases, Swedish University of Agricultural Sciences, S-750 07, Uppsala, Sweden. 